\title{
Effects of Energy Delivery Via a His Bundle Catheter during Closed Chest Ablation of the Atrioventricular Conduction System
}

\author{
Joey L. Trantham, John J. Gallagher, Lawrence D. German, \\ archer Broughton, Thomas Guarnieri, and Jack Kasell, \\ Division of Cardiology, Department of Medicine, Duke University \\ Medical Center, Durham, North Carolina 27710
}

A B S T R A C T In this paper we summarize our experience and report the characteristics of energy delivery in 23 patients who have undergone closed chest ablation of the normal atrioventricular (AV) conduction system for the treatment of refractory supraventricular arrhythmias. The induction of AV block was achieved by the synchronous delivery of electrical energy with a damped sinusoidal waveform utilizing a standard direct current defibrillator and a standard tripolar His bundle catheter. The procedure was well tolerated, though one patient experienced ventricular fibrillation, which was uneventfully converted with external paddles.

Complete AV block was achieved in 20 of 23 patients and all were rendered arrhythmia free, though two still required antiarrhythmic drugs. A stable escape rhythm was seen in all patients with a cycle length of $1,294 \pm 243 \mathrm{~ms}$. Creatine phosphokinase-MB was positive at low levels in 19 of 23 patients and cleared within $24 \mathrm{~h} .{ }^{99 \mathrm{~m}} \mathrm{Tc}$ pyrophosphate scans were faintly positive in only 2 of 22 patients. Left ventricular wall motion and ejection fractions were unchanged in 19 of 19 patients, two-dimensional echocardiography with microcavitation technique was unchanged in 12 of 12 patients, and a slight increase in pulmonary artery wedge pressure was seen in only 1 of 11 patients.

Current, voltage, and their product (power) waveforms were recorded in 12 patients $(12$ recordings at a defibrillator setting of $200 \mathrm{~J}$ and 5 recordings at a

Address reprint requests to Dr. John J. Gallagher, Heineman Medical Research Center and Sanger Clinic, Charlotte, NC 28207. Dr. Trantham's present address is Cardiology Consultants, Pensacola, FL 32501.

Received for publication 24 February 1983 and in revised form 6 July 1983. defibrillator setting of $300 \mathrm{~J}$ ) and revealed a complex voltage-current relationship due to changes occurring at the catheter electrode-tissue interface. At $200 \mathrm{~J}$ the peak values were $42.2 \pm 3.3 \mathrm{~A}, 2.16 \pm 0.11 \mathrm{kV}$, and $87.9 \pm 4.7 \mathrm{~kW}$, while at $300 \mathrm{~J}$ the peak values were $58.2 \pm 2.8 \mathrm{~A}, 2.40 \pm 0.10 \mathrm{kV}$, and $134.4 \pm 6.7 \mathrm{~kW}$, respectively. No instance of catheter disruption was seen, though "pitting" of the distal electrode (through which current passed) occurred in all but one catheter.

\section{INTRODUCTION}

Intentional interruption of the normal atrioventricular $(\mathrm{AV})^{1}$ conduction system in man for the treatment of refractory supraventricular arrhythmias was first reported in $1967(1,2)$. Since that time a number of methods have been used to interrupt the normal conduction system in man, including ligation of tissue near the AV node (1-4), electrocoagulation $(5,6)$, surgical dissection $(2,7)$, and cryosurgical freezing of tissue near the AV node and His bundle $(10,12)$. However, all of these procedures have required open heart surgery (1-13).

A variety of techniques for the closed chest interruption of $A V$ conduction in dogs have been reported (14-23), but only the delivery of electrical energy to the region of the His bundle has been reported as a technique for the closed chest interruption of the normal AV conduction system in man (24-28). The technique uses the delivery of electrical energy from a standard direct current defibrillator to the region of the His bundle through either a standard $(25,26)$ or

\footnotetext{
${ }^{1}$ Abbreviations used in this paper: AV, atrioventricular; $\mathrm{Cp}$, polarization capacitance; $\mathrm{Rp}$, polarization resistance.
} 
a specially designed $(27,28)$ His bundle catheter positioned fluoroscopically, as well as by recording the His potential. A similar technique, although at reduced levels of energy delivery, has recently been investigated in the coronary sinus of dogs $(29,30)$, and preliminary reports of its use in attempts to interrupt conduction over accessory AV pathways in patients with the Wolff-Parkinson-White syndrome have appeared (31). In addition, preliminary findings during attempts at electrode catheter ablation of foci of ventricular tachycardia have been reported (32).

Although the relationship of the level of energy delivered to achievement of the desired outcome has been emphasized (21-32), no reports of the characteristics of energy delivery through a catheter system at these levels of energy have appeared in the literature. In this paper we summarize our experience with this procedure in 23 patients, 9 of whom have been previously reported (25), and describe the characteristics of energy delivery through a His bundle catheter in 12 patients, recorded at the time of closed chest ablation of the normal AV conduction system for control of refractory supraventricular tachycardia. In addition, the characteristics of energy delivery to one patient undergoing transthoracic cardioversion for atrial flutter are presented and compared with the characteristics of energy delivery through a catheter.

\section{METHODS}

The protocol used at the Duke University Medical Center in the selection of patients as possible candidates for ablation of the normal AV conduction system $(10,25)$ has been previously reported. We use a standard tripolar electrode catheter (No. 6 French tripolar, United States Catheter and Instrument Corp., Billerica, MA) positioned in the region of the His bundle via the right femoral vein. In one patient, a No. 6 French tripolar His catheter (Electrocatheter Corp., Rahway, NJ) was used from the left subclavian vein. After sedation, and when the best possible catheter position was achieved, the distal pole was rapidly switched to the output of a Physio-Control LifePak 6 defibrillator set to $200 \mathrm{~J}$ of energy, which was then discharged synchronously to a standard $12-\mathrm{cm}$ diam backpaddle covered with electrode paste and positioned beneath the left scapula.

After delivery of energy, demand ventricular pacing was instituted and, following the appearance of an escape rhythm, the possibility of continued conduction over the His bundle was investigated. If conduction over the His bundle resumed either spontaneously or following atropine ( $2 \mathrm{mg}$ i.v.) and isoproterenol (up to $3 \mu \mathrm{g} / \mathrm{min}$ i.v.), a shock with the defibrillator set to $300 \mathrm{~J}$ was delivered in a similar manner and, if necessary, an additional $300 \mathrm{~J}$ shock. Although not done initially, new catheters are now used for each energy delivery. Approximately $48 \mathrm{~h}$ after the procedure, a permanent transvenous pacing system was implanted.

The possibility of myocardial damage resulting from the energy delivery was investigated by serial creatine phosphokinase isoenzymes for $48 \mathrm{~h}$ as well as a ${ }^{99 \mathrm{~m}} \mathrm{Tc}$ pyrophosphate scan $72 \mathrm{~h}$ after energy delivery. In addition, two-dimensional echocardiography with microcavitation tech- nique was performed before and $72 \mathrm{~h}$ after the procedure to assess the tricuspid valve.

Energy measurement. Simultaneous recordings of voltage, current, and their instantaneous product (power) waveforms were obtained at the instant of energy delivery on a Tektronix 5113 dual-beam storage oscilloscope (Tektronix, Inc., Beaverton, OR) equipped with two $5 \mathrm{Al} 4 \mathrm{~N}$ four-channel vertical amplifiers (frequency response $\mathrm{DC}-1 \mathrm{MHz}$ ) and a $5 \mathrm{~B} 12 \mathrm{~N}$ dual time base (oscilloscope sweep $1 \mathrm{~ms} /$ division). The display was recorded photographically with a Tektronix C59A oscilloscope camera for later analysis.

Voltage recordings were made in a differential manner with a circuit providing high input impedance $(20 \mathrm{M} \Omega)$ to minimize leakage currents to the patient and to maintain the direct current defibrillator isolated from alternating current ground. The voltage signal was scaled by a factor of 1,000 , providing a signal of $1 \mathrm{~V} / \mathrm{kV}$ to the oscilloscope and to one input of a four-quadrant-analog multiplier (model AD532KD, Analog Devices Inc., Norwood, MA). The current waveform was recorded by a Tektronix A6303 current probe (equivalent insertion impedance $=0.02 \Omega$ at $1 \mathrm{MHz}$ ) that was connected to a Tektronix AM503 current probe amplifier (frequency response DC-5 MHz). The output voltage of the current probe amplifier was amplified to provide a signal of $0.1 \mathrm{~V} / \mathrm{A}$ to the oscilloscope and to the other input of the analog multiplier. The power waveform was generated by the AD532KD four-quadrant-analog multiplier (frequency response DC-1 $\mathrm{MHz}$ ) and represented the product of the voltage and current waveforms scaled by a factor of $10(0.01$ $\mathrm{V} / \mathrm{kW}$ ). The total energy delivered was calculated by integrating the power waveform using a digitized graph pen and a digital computer. The instantaneous voltage-to-current ratio (impedance) during energy delivery was generated from the photographic record by measuring the value of voltage and current at various times during the recorded energy delivery. The effect of current delivery on the His bundle catheter was investigated after the procedure, by measuring the interelectrode resistance as well as the resistance of the connections between the catheter connectors and the electrodes at the tip. Changes occurring at the distal electrode, through which current passed, were investigated by photomicroscopy.

\section{RESULTS}

Patient population. We have performed the procedure just described in 23 patients, age 29-76 yr (mean $54 \mathrm{yr}$ ), presenting with refractory supraventricular tachyarrhythmias (atrial flutter/fibrillation with a rapid ventricular response in eight patients, reciprocating tachycardia due to an accessory pathway in nine patients, and reciprocating tachycardia due to reentry confined to the AV node in six patients). 9 of the 23 patients have been previously reported (25).

Complete heart block was achieved with the initial 200-J shock in 14 of 22 patients and with an additional $300-\mathrm{J}$ shock in 5 of the remaining 8 patients. In only 3 of 22 patients (1 receiving a single 200-J shock, 1 receiving a $200-\mathrm{J}$ shock followed by a single $300-\mathrm{J}$ shock, and 1 receiving a $200-\mathrm{J}$ shock followed by two $300-\mathrm{J}$ shocks) was the attempt at AV node-His bundle interruption unsuccessful. AV conduction returned after 3 $\mathrm{d}, 4 \mathrm{~d}$, and $12 \mathrm{~h}$, respectively; however, a subsequent 
evaluation demonstrated significant modification of AV conduction, rendering them arrhythmia free.

Follow-up is complete for a period ranging from 2 wk to 14.5 mo (mean $7.8 \mathrm{mo}$ ) and no apparent adverse effects resulting from the shock have been observed. 22 of 23 patients remain well and free of arrhythmia. Only two are currently on antiarrhythmic medications. 1 of the 23 patients died $\sim 2$ mo following ablation, as a result of combined severe chronic obstructive pulmonary disease and chronic congestive heart failure.

Characteristics of the escape rhythm. Recovery times could be assessed following pacemaker inhibition in 17 of 22 patients (excluding the 3 patients with modified AV conduction and 2 patients with manifest preexcitation over accessory pathways). At a rate of $70 / \mathrm{min}$, an escape beat was observed in 16 of 17 patients at intervals of 1,040-6,200 ms (mean 2,524 ms); in 1 patient, with sick sinus syndrome, pacing was reinstituted when no escape was observed after $8 \mathrm{~s}$ (an escape was subsequently observed after pacing at a rate of 50 / $\mathrm{min}$ ). A subsidiary escape rhythm was observed in all patients following the procedure either during heart block (transient in three patients) or during periods of sinus slowing in the two patients with manifest preexcitation. The stable cycle length of this escape rhythm averaged $1,294 \pm 243 \mathrm{~ms}$. The QRS morphology was unchanged in 10 of 23 patients and exhibited incomplete or complete right bundle branch block morphology in 10 and incomplete or complete left bundle branch block morphology in 3 .

Assessment of myocardial damage. Myocardial damage as a result of the procedure appeared minimal. Creatine phosphokinase-MB was positive in 19 of 23 patients with peak levels ranging from 13 to $166 \mathrm{IU}$ with an average level of $48 \mathrm{IU}$ detectable within 12 $\mathrm{h}$ and clearing by $24 \mathrm{~h}$. A ${ }^{99 \mathrm{~m}} \mathrm{Tc}$ pyrophosphate scan was positive in only 2 of 22 patients scanned and consisted of a trace amount of activity. Ejection fraction and wall motion by radionuclide technique was unchanged in 19 of 19 patients. There was no evidence of tricuspid thrombus, regurgitation, or septal defect by two-dimensional echocardiography in 12 of 12 patients. Finally, a Swan-Ganz catheterization performed before ablation and during ventricular pacing at least $\mathbf{4 0} \mathrm{min}$ after ablation was unchanged in 10 of 11 patients; in the remaining patient, a slight rise in wedge pressure was observed. No complications were encountered acutely with the exception of precipitation of ventricular fibrillation with the 200-J synchronous shock in one patient. This was uneventfully converted by external paddles.

Characteristics of energy delivery. Recordings were obtained during the initial attempt at His bundle ablation from 12 patients, the results of which are summarized in Table I. The results are divided into those that were successful with the initial attempt (eight patients) and those that were not (four patients). No characteristic of energy delivery could be found that allowed the identification of a successful AV node-His bundle ablation.

A typical recording of an energy delivery at $200 \mathrm{~J}$ is shown in Fig. 1. The "smooth" damped sinusoidal waveforms typical of transthoracic energy delivery or energy delivery to a $50-\Omega$ dummy load (33) were never seen during recordings of energy delivery through a His bundle catheter.

Energy delivery at a defibrillator setting of $200 \mathrm{~J}$. For the group, peak current was $42.2 \pm 3.3 \mathrm{~A}$, peak voltage was $2.16 \pm 0.11 \mathrm{kV}$, and peak power was $87.9 \pm 4.7 \mathrm{~kW}$. Total energy delivered was $194 \pm 11 \mathrm{~J}$ as calculated by integration of the power curve. Of significance is the finding that current peaked later than voltage $(1.27 \pm 0.11 \mathrm{~ms}$ for current vs. $1.08 \pm 0.09$ $\mathrm{ms}$ for voltage, $P<0.01$ by Student's $t$ test) in all but one patient, suggesting a variable impedance during energy delivery. Power peaked $1.15 \pm 0.04 \mathrm{~ms}$ after the onset of energy delivery.

A representative record of energy delivery at a setting of $200 \mathrm{~J}$ is shown in Fig. 1 (patient 2). As can be seen, voltage increased rapidly in the initial portion of the energy delivery, reaching $2 \mathrm{kV}$ after $\sim 0.5 \mathrm{~ms}$. Voltage continued to increase but at a much slower rate, again suggesting a variable impedance during energy delivery, reaching a peak of $2.2 \mathrm{kV}$ at $1.2 \mathrm{~ms}$. Current on the other hand, increased at a somewhat more linear though decreasing rate reaching a peak of $42 \mathrm{~A}$ at $1.3 \mathrm{~ms}$. Power, the product of voltage and current, peaked at $91 \mathrm{~kW}$ at $1.2 \mathrm{~ms}$.

After the peak of current, voltage, and power all three quantities decreased toward the base line. However, evidence of a late potential of $\sim 0.4 \mathrm{kV}$ was seen up to $9 \mathrm{~ms}$ after the onset of energy delivery, compatible with a component of capacitive reactance in the load seen by the defibrillator. Current decreased to $\sim 2 \mathrm{~A}$ and power decreased to $\sim 0.8 \mathrm{~kW}$ at $9 \mathrm{~ms}$, compatible with an increasing resistive component of the load seen by the defibrillator. Total energy delivered to this patient was $204 \mathrm{~J}$, with almost all energy being delivered within the first $5 \mathrm{~ms}$ of energy delivery.

As mentioned earlier, a different time course of voltage and current was a consistent finding, suggesting a variable impedance during energy delivery. In patient 2 , at a setting of $200 \mathrm{~J}$, the minimum impedance was $51 \Omega$ and occurred at $1.75 \mathrm{~ms}$, well after the peak of current, voltage, and power. Subsequently, the voltageto-current ratio increased, reaching a late value of 200 $\Omega$. The impedance curves for all patients during the 200-J shock are shown in Fig. 2. As can be seen the impedance when first measured at $\sim 0.25 \mathrm{~ms}$ was $\sim 75$ $\Omega$ in all patients except patient 3 , who demonstrated 
TABLE I

Energy Measurement-Defibrillator Setting of $200 \mathrm{~J}$

\begin{tabular}{|c|c|c|c|c|c|c|c|c|c|c|}
\hline \multirow[b]{2}{*}{ Patient } & \multicolumn{6}{|c|}{ Peak values } & \multirow{2}{*}{$\int_{0}^{\infty} \mathrm{P}(t) \mathrm{d} t$} & \multicolumn{3}{|c|}{ Impedance } \\
\hline & I & Time & $\mathbf{v}$ & Time & $\mathbf{P}$ & Time & & Minimum & Time & Late (>7 ms) \\
\hline & $A$ & ms & $k V$ & $m s$ & $k W$ & ms & $J$ & $\mathbf{\Omega}$ & ms & $\mathbf{\Omega}$ \\
\hline \multicolumn{11}{|c|}{ Initial attempt successful } \\
\hline 1. B.S. & 40 & 1.30 & 2.20 & 0.95 & 80 & 1.10 & 181 & 44 & 3.00 & 167 \\
\hline 2. C.O. & 42 & 1.30 & 2.20 & 1.20 & 91 & 1.20 & 204 & 51 & 1.75 & 200 \\
\hline 3. D.A. & 52 & 1.25 & 1.85 & 1.10 & 94 & 1.15 & 188 & 35 & 1.25 & 100 \\
\hline 4. R.B. & 41 & 1.20 & 2.20 & 1.20 & 90 & 1.20 & 206 & 53 & 1.45 & 175 \\
\hline 5. C.G. & 40 & 1.20 & 2.20 & 1.10 & 87 & 1.15 & 201 & 55 & 1.10 & 225 \\
\hline 6. W.B. & 40 & 1.20 & 2.25 & 1.00 & 90 & 1.15 & 201 & 54 & 1.60 & 275 \\
\hline 7. W.H. & 41 & 1.25 & 2.20 & 1.00 & 88 & 1.20 & 199 & 53 & 1.60 & 400 \\
\hline 8. B.M. & 42 & 1.20 & 2.20 & 1.05 & 92 & 1.15 & 201 & 51 & 1.75 & 275 \\
\hline Mean & 42.3 & 1.24 & 2.16 & 1.08 & 89.0 & 1.16 & 198 & 49.5 & 1.69 & 227 \\
\hline SD & 4.0 & 0.04 & 0.13 & 0.09 & 4.2 & 0.04 & 9 & 6.8 & 0.58 & 91 \\
\hline \multicolumn{11}{|c|}{ Initial attempt unsuccessful } \\
\hline 9. L.G. & 41 & 1.50 & 2.20 & 1.10 & 80 & 1.10 & 175 & 48 & 1.75 & 155 \\
\hline 10. R.L. & 42 & 1.15 & 2.10 & 0.95 & 83 & 1.10 & 176 & 50 & 1.50 & 200 \\
\hline 11. L.L. & 44 & 1.45 & 2.10 & 1.15 & 88 & 1.15 & 192 & 43 & 2.00 & 200 \\
\hline 12. H.L. & 41 & 1.25 & 2.25 & 1.10 & 92 & 1.10 & 202 & 53 & 1.75 & 200 \\
\hline Mean & 42.0 & 1.34 & 2.16 & 1.08 & 85.8 & 1.11 & 186 & 48.5 & 1.75 & 189 \\
\hline SD & 1.4 & 0.17 & 0.08 & 0.09 & 5.3 & 0.03 & 13 & 4.2 & 0.20 & 23 \\
\hline \multicolumn{11}{|l|}{ Combined } \\
\hline Mean & 42.2 & 1.27 & 2.16 & 1.08 & 87.9 & 1.15 & 194 & 49.2 & 1.71 & 214 \\
\hline SD & 3.3 & 0.11 & 0.11 & 0.09 & 4.7 & 0.04 & 11 & 5.8 & 0.47 & 76 \\
\hline
\end{tabular}

I, current; V, voltage; $P$, power.

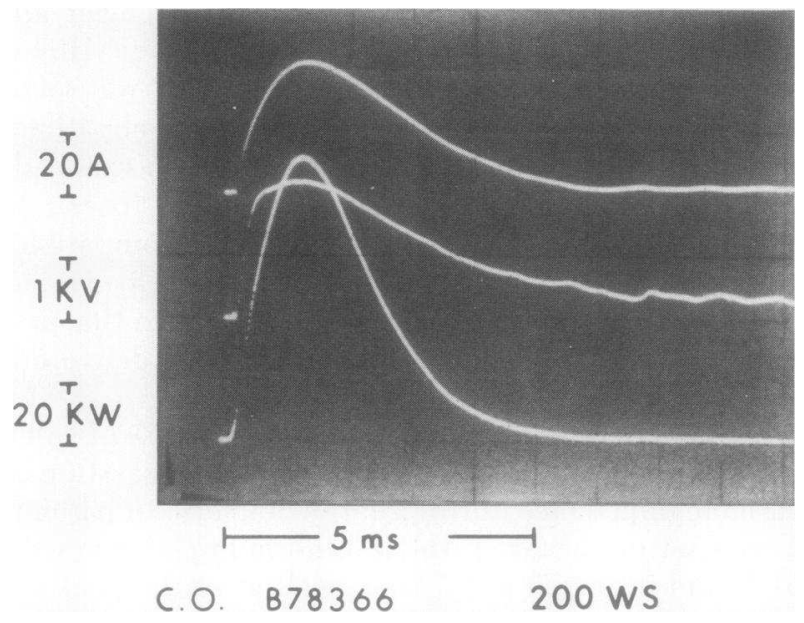

Figure 1 Typical recording of current, voltage, and power during His bundle ablation using $200 \mathrm{~J}$ in patient 2 . Note that current peaks later than voltage, with power peaking in between. Also note that voltage rises abruptly then slows at $\sim 2 \mathrm{kV}$ while the current waveform is smoother. WS (Watt second) $=1 \mathrm{~J}$. the lowest impedance, highest current, and lowest voltage of any patient during the initial shock. For the group, impedance demonstrated an initial decline to a minimum of $49.2 \pm 5.8 \Omega$ at $1.71 \pm 0.47 \mathrm{~ms}$ followed by a subsequent increase to $214 \pm 76 \Omega$ for times $>7 \mathrm{~ms}$.

Energy delivery at a defibrillator setting of $300 \mathrm{~J}$. During energy delivery at a setting of $300 \mathrm{~J}$, a relationship between current and voltage was observed that was similar to that seen at a setting of $200 \mathrm{~J}$ and is summarized in Table II. For the group, peak current was $58.2 \pm 2.8 \mathrm{~A}$, peak voltage was $2.40 \pm 0.10 \mathrm{kV}$, and peak power was $134.4 \pm 6.7 \mathrm{~kW}$. The total energy delivered was $282 \pm 10 \mathrm{~J}$ and, as seen at a setting of 200 $\mathrm{J}$, current peaked later than voltage $(1.30 \pm 0.08 \mathrm{~ms}$ for current vs. $1.10 \pm 0.16 \mathrm{~ms}$ for voltage, $P=0.056$ ). However, at $300 \mathrm{~J}$, the peak power occurred later $(1.25 \pm 0.07$ $\mathrm{ms}$ at a setting of $300 \mathrm{~J}$ vs. $1.15 \pm 0.04 \mathrm{~ms}$ at a setting of $200 \mathrm{~J}, P<0.01$ ) and the minimum impedance was lower $(39.2 \pm 4.8 \Omega$ at a setting of $300 \mathrm{~J}$ vs. $49.2 \pm 5.8 \Omega$ at a setting of $200 \mathrm{~J}, P=0.01$ ). In addition, the minimum impedance tended to be reached sooner and the late 


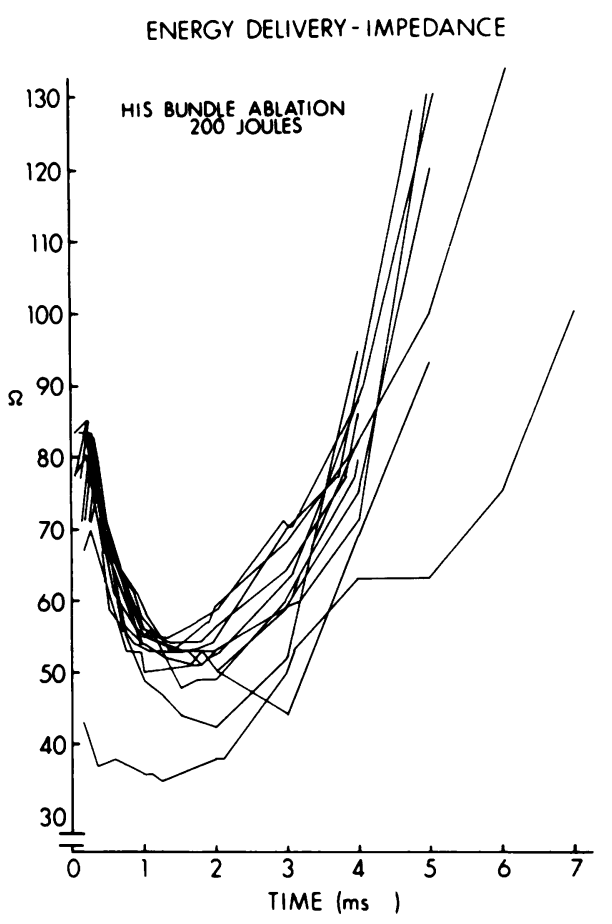

Figure 2 Impedance during His bundle ablation at a defibrillator setting of $200 \mathrm{~J}$. Note initial decrease in impedance from $\sim 75 \Omega$ to a minimum of $49.2 \pm 5.8 \Omega$ at $1.71 \pm 0.47 \mathrm{~ms}$ after onset of energy delivery followed by a rapid increase in impedance late in the energy delivery.

impedance tended to be higher at $300 \mathrm{~J}$ than that seen at $200 \mathrm{~J}$.

The impedance data during the $300-\mathrm{J}$ shock are summarized in Fig. 3. As can be seen, the impedance at $\sim 0.25 \mathrm{~ms}$, when it could first be calculated, was $\sim 65$ $\Omega$ for all patients except for the second $300-\mathrm{J}$ shock for patient 10 , who demonstrated the earliest minimum

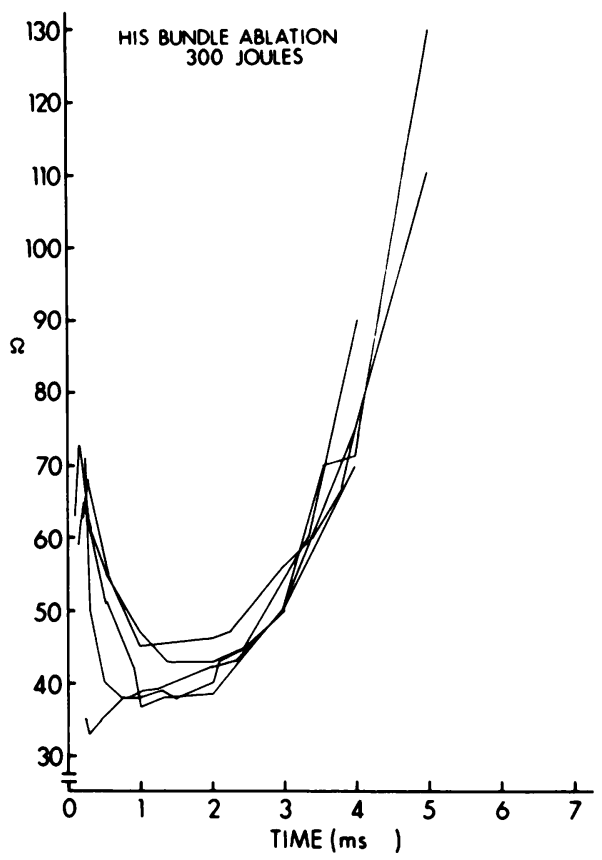

Figure 3 Impedance during His bundle ablation at a defibrillator setting of $300 \mathrm{~J}$. Compare with Fig. 2. Note similar shape of curve but with initial impedance and minimum impedance being lower and minimum impedance occurring earlier than at a defibrillator setting of $200 \mathrm{~J}$. See text for discussion.

and lowest impedance of any patient during a 300-J shock. For the group the minimum impedance during the $300-\mathrm{J}$ shock was $39.2 \pm 4.8 \Omega$ and occurred at $1.11 \pm 0.56 \mathrm{~ms}$. The impedance subsequently increased to $260 \pm 55 \Omega$ late $(>7 \mathrm{~ms})$ in the energy delivery. As

TABLE II

Energy Measurement-Defibrillator Setting of $300 \mathrm{~J}$

\begin{tabular}{|c|c|c|c|c|c|c|c|c|c|c|}
\hline Patient & 1 & Time & $\mathbf{v}$ & Time & $\mathbf{P}$ & Time & $\int_{0}^{\infty} P(t) d t$ & Minimum & Time & Late (>7 ms) \\
\hline 9. L.G. & 56 & 1.35 & 2.50 & 1.00 & 125 & 1.30 & 282 & 43 & 1.75 & 200 \\
\hline 10. R.L. No. 1 & 62 & 1.30 & 2.40 & 1.30 & 143 & 1.30 & 281 & 38 & 1.00 & 300 \\
\hline 12. H.L. & 55 & 1.25 & 2.50 & 1.10 & 138 & 1.15 & 296 & 45 & 1.00 & 200 \\
\hline Mean & 58.2 & 1.30 & 2.40 & 1.10 & 134.4 & 1.25 & 282 & 39.2 & 1.11 & 260 \\
\hline SD & 2.8 & 0.08 & 0.10 & 0.16 & 6.7 & 0.07 & 10 & 4.8 & 0.56 & 55 \\
\hline
\end{tabular}

I, current; V, voltage; $P$, power. 
mentioned earlier, the different time course of voltage and current suggests a variable impedance during energy delivery, but the different values at defibrillator settings of 200 and $300 \mathrm{~J}$ suggests a complex impedance rather than a purely resistive load.

Effect of energy delivery on the His bundle catheter. Energy was delivered through the distal electrode in all patients. All catheters demonstrated evidence of high current discharge, as shown by "pitting" of the distal electrode with similar degrees of pitting for both 200 and $300 \mathrm{~J}$. The pitting of the distal electrode was usually localized to the side facing the observer, as viewed with the catheter lying on a table and curving to the right (i.e., the blood cavity side). Occasionally the pitting was localized to the superior aspect of the distal electrode. The pitting invariably was at the junction of the electrode and insulating material of the catheter, sparing the distal tip of the electrode. Interestingly, the catheter used in patient 3 , who demonstrated the lowest impedance and highest current of any patient receiving a 200-J shock, demonstrated minimal evidence of pitting, suggesting a more uniform distribution of current density.

There was no evidence of catheter disruption during any of the procedures. Early in the study, however, open circuits in the connecting wires to the distal electrode occurred in three catheters that had been used in previous energy delivery. Records of energy delivery at the time an open circuit occurred demonstrated no significant difference from the records obtained when no open circuit occurred, suggesting the open circuits resulted from thermal disruption after energy delivery was complete. Since the institution of the policy of using only new catheters for each energy delivery, no open circuits have occurred.

A portion of the energy delivered to the catheter appeared to exit the catheter at the middle or proximal poles, as shown by occasional small areas of pitting of these electrodes on two catheters and "arcs" from the proximal poles seen on photographic records of test energy deliveries in normal saline. However, evidence of a significant decrease in interelectrode resistance was found in only one catheter early in the series during a successful 200-J shock. Energy delivery was not recorded in this instance, and a measurable loss of interelectrode insulation has not been seen since using new catheters for each energy delivery. These data suggest that the energy is being coupled to the connecting wires of the proximal poles via a capacitive effect, and that interelectrode insulation breakdown is more likely to occur with older catheters, perhaps as a result of deterioration of dielectric properties.

Effect of energy delivery through a catheter on energy measurements and comparison with transthoracic energy delivery. To investigate the effect of the catheter on the characteristics of energy delivery as measured by our technique, we measured the characteristics of a shock at a defibrillator setting of 200 $\mathrm{J}$ to a standard (model 5073, American Optical Scientific Instruments, Buffalo, NY) 50- $\Omega$ dummy load through both a standard His bundle catheter and a heavy (12 gauge) cable of similar length. The recordings demonstrated "smooth" damped sinusoidal waveforms (33). As summarized in Table III, current and voltage peaked at different times but, in contrast to that seen in patients undergoing His bundle ablation, current peaked earlier than voltage. This is reflected by the impedance curve during the energy delivery shown in Fig. $4 \mathrm{~A}$. As can be seen, the impedance curves obtained are almost identical for both the catheter and the cable, suggesting that the connecting wires within the catheter have no significant effect on energy delivery. The fact that the impedance waveform obtained rises during energy delivery is explained by the fact that the dummy load is constructed of a wire-wound resistor whose interwinding capacitance acts as an initial short circuit until these capacitors are charged.

For comparison, a recording was made of a $200-\mathrm{J}$ shock to a 32 -yr-old, $62-\mathrm{kg}, 161-\mathrm{cm}$ female undergoing elective cardioversion for atrial flutter. Energy was delivered via a standard anterior paddle ( 7.5 by 12.5

TABLE III

Energy Measurement-Defibrillator Setting of $200 \mathrm{~J}$

\begin{tabular}{|c|c|c|c|c|c|c|c|c|c|c|}
\hline & \multicolumn{6}{|c|}{ Peak } & \multirow{2}{*}{$\int \mathrm{P}(t) \mathrm{d} t$} & \multicolumn{3}{|c|}{ Resistance } \\
\hline & I & Time & $\mathbf{v}$ & Time & $\mathbf{P}$ & Time & & Minimum & Time & Late \\
\hline & $A$ & $m s$ & $k V$ & $m s$ & $k W$ & $m s$ & $J$ & $\mathbf{\Omega}$ & $m s$ & $\mathbf{\Omega}$ \\
\hline $50-\Omega$ dummy load-cable & 44 & 1.0 & 2.2 & 1.2 & 93 & 1.05 & 182 & 30 & 0.25 & 58 \\
\hline $50-\Omega$ dummy load-catheter & 44 & 1.0 & 2.3 & 1.1 & 100 & 1.05 & 208 & 25 & 0.25 & 58 \\
\hline Anteroposterior paddles, atrial flutter & 46 & 1.1 & 2.1 & 1.1 & 92 & 1.1 & 185 & 37 & 0.35 & 53 \\
\hline
\end{tabular}

I, current; V, voltage; $P$, power. 


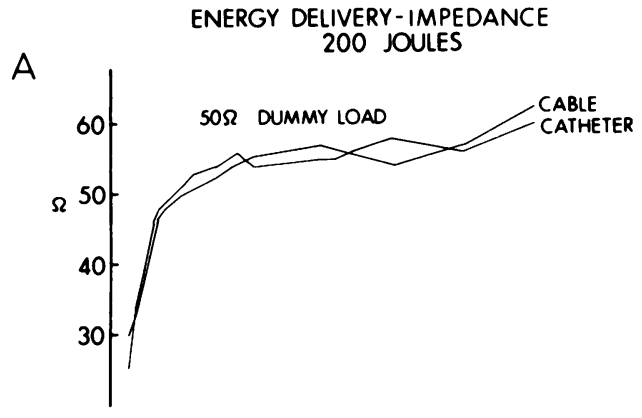

B

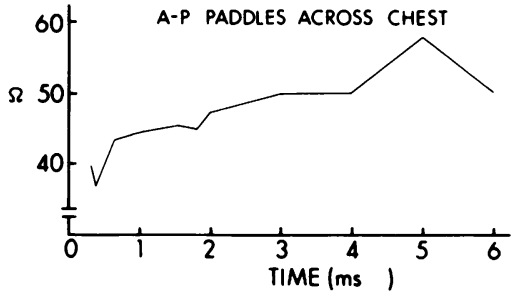

Figure 4 Impedance curves for energy deliveries at a defibrillator setting of $200 \mathrm{~J}$ to a $50-\Omega$ dummy load through either a standard catheter or a heavy (12 gauge) cable or during transvenous cardioversion. (A) Energy deliveries to a dummy load. (B) Transthoracic energy delivery. Note relatively constant impedance after peak of current, voltage, and power (i.e., $>1 \mathrm{~ms}$ ). See text for discussion.

$\mathrm{cm})$ and posterior paddle (12-cm diam) both covered with electrode paste. The recording again demonstrated smooth damped sinusoidal waveforms (33). As summarized in Table III, voltage and current peaked simultaneously, indicating a relatively constant impedance during energy delivery. The impedance curve during this shock is shown in Fig. $4 \mathrm{~B}$.

Of note is the fact that during energy delivery to both the dummy load and across the chest, at the time of peak voltage and current and later during the energy delivery, the impedance is quite stable at $\sim 50$ $\Omega$, while during His bundle ablation the minimum impedance is not seen until after the peak current at $200 \mathrm{~J}$ and at or slightly before the peak current at 300 J. The significance of these observations will be discussed later.

\section{DISCUSSION}

Clinical implications. The success of catheter ablation of the normal AV conduction system ( 20 of 23 patients) is comparable to that obtained at open heart surgery (10). In addition, the three patients in whom interruption of the normal conduction system was not achieved were symptomatically improved. Our experience to date supports the safety of this procedure.
The potential risks involved in this procedure are related to mechanical trauma to the septal structures, possible arrhythmogenesis, and the possibility of pacemaker dependence. No evidence of tricuspid insufficiency, ventricular or atrial septal defect, or thromboembolic events have been found in our patients. The arrhythmogenic potential of this procedure appears to be small, as evidenced by the relatively small size of the lesions reported in studies in experimental animals (21-23) and lack of significant myocardial damage in clinical studies (25-28). Although the peak current delivered is comparable to that during a transthoracic cardioversion of equal energy (34), the current density achieved across the heart would be expected to be higher during energy delivery through a His bundle catheter and therefore perhaps more likely to induce myocardial injury (34). However, we feel that no evidence exists to suggest an arrhythmogenic sequella to this procedure.

The control of refractory supraventricular arrhythmias by this technique requires the possibility of pacemaker dependence. We utilize a setting of $200 \mathrm{~J}$ at the initial attempt at His bundle ablation and our patients have exhibited preservation of a good subsidiary escape rhythm $(25,26)$ as described here. Scheinman et al. (28) have reported the use of two successive 500$\mathrm{J}$ energy deliveries and have reported a slightly slower escape rate with a wide QRS complex in all patients, perhaps due to greater damage to the underlying escape mechanism. The long-term stability of the escape mechanism remains to be defined, but preliminary reports suggest it to be satisfactory, especially in those patients in whom the escape QRS morphology is unchanged or demonstrates a left bundle branch block morphology (35).

Characteristics of energy delivery. The impedance data generated during these recordings indicate a complex relationship between voltage and current and require a complex impedance (both resistive and reactive components) rather than a pure resistance to model the characteristics of energy delivery. For transthoracic energy delivery however, a fixed, purely resistive model would perhaps be acceptable.

The Physio-Control LifePak 6 defibrillator utilizes an energy storage capacitor that is discharged via a series inductor through the paddles to generate a damped sinusoidal waveform. A simplified schematic diagram of the output circuit of the defibrillator is shown in Fig. $5 \mathrm{~A}$ along with the general equations for the current, voltage, and power waveforms for a fixed resistance load. A graph of the solution of these equations, at $200 \mathrm{~J}$ energy stored, for various purely resistive loads connected to a Physio-Control LifePak 6, is shown in Fig. 5 B. As can be seen, the timing and 


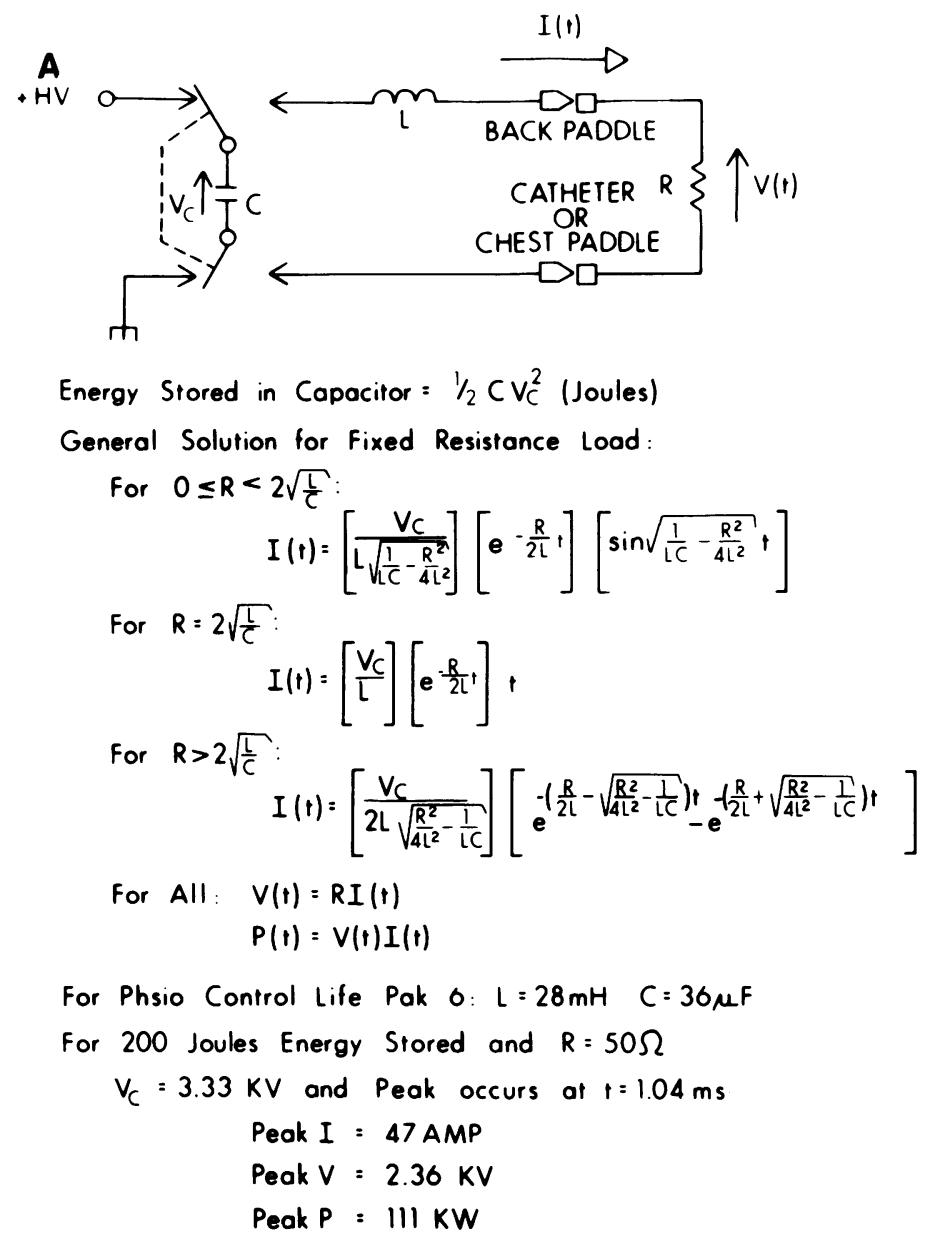

Figure 5 (A) Simplified circuit diagram and general solution for current, voltage, and power waveforms for de defibrillator. (B) Solution for 200-J energy stored at various fixed resistive loads for the Physio-Control LifePak 6 used in this study. Plotted points represent solution obtained by choosing impedance and time from curves shown in Fig. 2. See text for discussion.

magnitude of the current and voltage peaks as well as the exact shape of the waveform depends on the value of the load resistance. However, the curves are smooth and at $50 \Omega$, are quite similar to those seen during transthoracic cardioversion or energy delivery to a dummy load. For a fixed, purely resistive (no capacitive or inductive reactance) load, peak current, voltage, and power occur simultaneously. The peak is earliest for high resistance and latest for low resistance. The lower the resistance, the higher the peak current and the lower the peak voltage. For power, a more complex relationship is seen. The highest peak power is seen with a load of $\sim 30 \Omega$ with lower values of peak power with higher or lower values of resistance.

This family of curves can be used to obtain an approximation of the current, voltage, and power curves seen in our patients, by choosing the appropriate value of current, voltage, and power at various times during energy delivery, from the curve suggested by the impedance value at that particular time during the energy delivery. For a 200-J shock, the result of such a process is shown in Fig. $5 \mathrm{~B}$. As can be seen, a purely resistive load, whose magnitude varies with time, can generate a current and voltage waveform with the relationship observed in our measurements, i.e., current peaking later than voltage. However, the lower minimum value of impedance and the different time course of change in impedance at a setting of $300 \mathrm{~J}$ require a complex impedance to adequately account for all observations at both 200 and $300 \mathrm{~J}$.

Although our test energy deliveries to a $50-\Omega$ dummy load and our transthoracic energy measurements failed to reveal any evidence of a direct effect of the catheter per se, such a complex impedance has been previously 


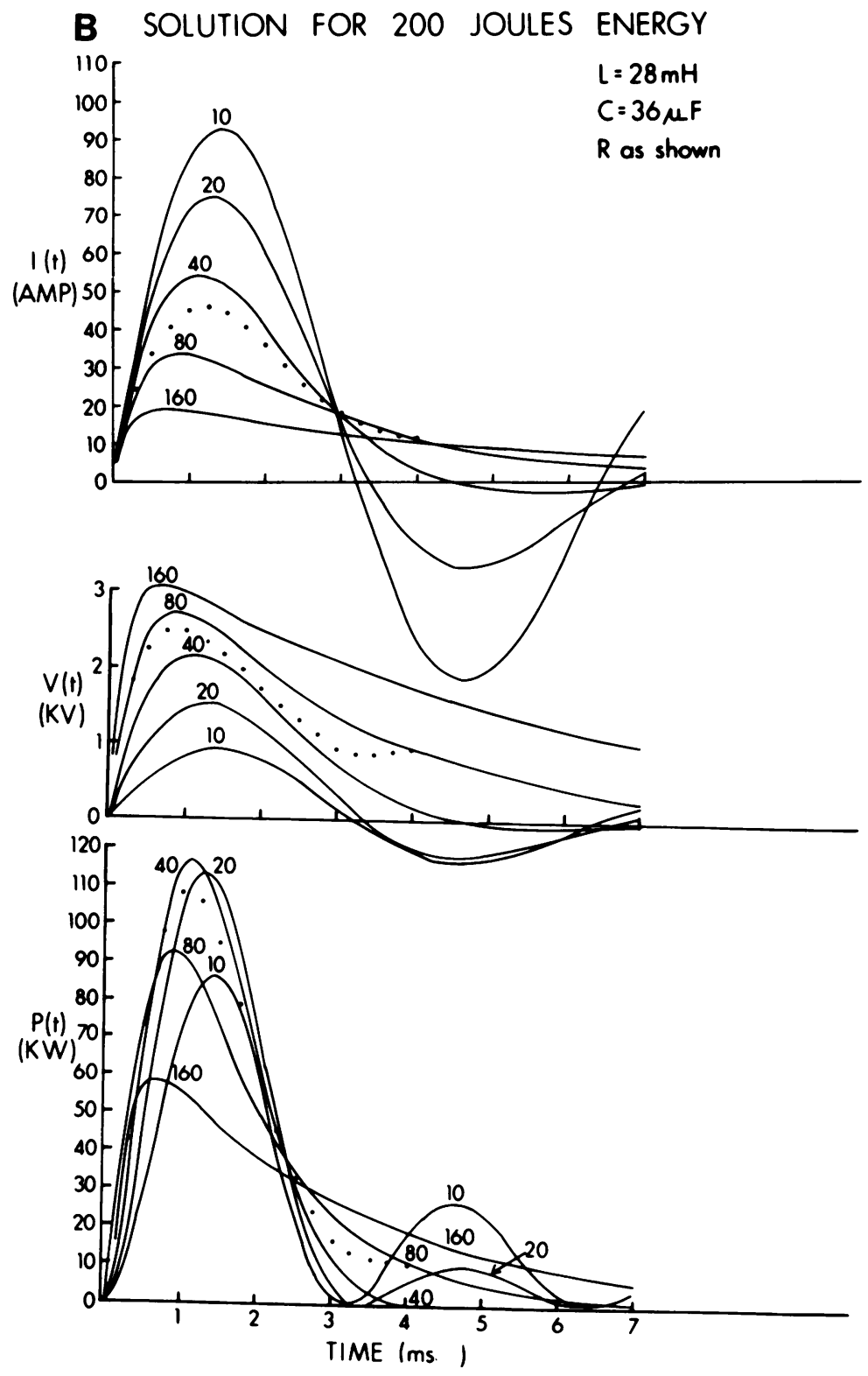

Figure 5 (Continued)

reported at the electrode-tissue interface (36) for lower levels of energy delivery used in cardiac-pacing applications. Although not accurate at the higher energy levels used here, the concepts presented there can be extended to advance a theory to describe the events occurring at the electrode-tissue interface at higher levels of energy delivery. A polarization capacitance $(\mathrm{Cp})$, in parallel with a polarization resistance, created at the interface by the depletion of charge carriers during current flow, would be expected to increase in value with higher currents and longer duration of cur- rent flow (36). The polarization resistance (Rp), due to resistance to charge flow into the solution, would be expected to increase with longer duration of current flow but decrease with higher current flow (36). A solution resistance, remote from the electrode-tissues interface, would be expected to remain relatively constant or increase with longer duration of current flow, but decrease with higher current flow. Therefore, the initial fall in the voltage-to-current ratio, as seen with both 200- and 300-J shocks, could be explained by an initial increase in $\mathrm{Cp}$ and fall in $\mathrm{Rp}$, as the magnitude of 
current flow increases. The subsequent increase in impedance could be explained by an increase in $R p$, as the duration of current flow increases and the magnitude of current flow decreases. The lower minimum value at $300 \mathrm{~J}$ would be expected to result from a greater increase in $\mathrm{Cp}$ and greater decrease in $\mathrm{Rp}$ due to the greater magnitude of current flow at $300 \mathrm{~J}$. The tendency toward a higher late value of impedance at a setting of $300 \mathrm{~J}$ would be expected to be due to a larger $\mathrm{Cp}$, charged to a higher voltage than that at $200 \mathrm{~J}$.

The apparent location of the highest current discharge on the distal electrode as shown by the pitting of the distal electrode may be explained by the different conductances of the tissues in close apposition to the distal electrode. The conductance of blood has been reported to be approximately three times greater than that of myocardium (37), thus perhaps providing a preferential path for current into blood. Whether this represents a disadvantage during attempts at His bundle ablation is unclear. Some investigators have reported the use of insulation to cover the area of the distal electrode $(21,22,27,28)$ apparently most frequently pitted on our catheters to increase the current entering the myocardium (28). However, they have required higher energy deliveries to achieve the desired results $(27,28)$. Current flow into blood, however, may provide a mechanical force to keep the distal electrode against the region of the His bundle during energy delivery or the symmetrical geometry of our distal electrode might result in a higher current density at the site of tissue destruction, thus making current delivery into the ventricular myocardium more efficient and allowing lower total energy deliveries with our standard tripolar catheter. Fluoroscopy during energy delivery in our patients has revealed little, if any, movement of the catheter. Alternatively, a quadripolar catheter (28) might permit more coupling of energy to the unused poles, or the torque often required to position a His bundle catheter might rotate the insulated portion of the distal electrode to the myocardial surface, thus requiring a higher energy delivery with the specially constructed catheter.

Although the different conductances of blood and myocardium (37) might be expected to result in different characteristics of energy delivery in successful vs. unsuccessful attempts at His bundle ablaticn, such was not the case in our measurements.

The lack of pitting on the catheter used in patient 3 suggests a more uniform current density over the surface of the distal electrode than that seen in other patients. Assuming a uniform current density over the distal electrode, and assuming all current entering the catheter is delivered through the distal electrode, energy delivery at a setting of $200 \mathrm{~J}$ would generate a peak current density of $\sim 2 \mathrm{~A} / \mathrm{mm}^{2}$ compared with a current density of $\sim 4 \times 10^{-3} \mathrm{~A} / \mathrm{mm}^{2}$ at the backpaddle. The presence of pitting, indicating thermal disruption of the electrode material, suggests an even higher current density in the affected area of the distal electrode.

The lower ratio of energy delivered to energy selected on the front panel control of the LifePak 6 defibrillator at $300 \mathrm{~J}$ (282 J delivered vs. $194 \mathrm{~J}$ delivered when $200 \mathrm{~J}$ selected) is due to the fact that the energy storage capacitor and series inductor are not ideal circuit elements but rather have a measurable resistance. The voltage to which the storage capacitor is charged is adjusted to result in an energy delivery equal to that selected by the front panel control only when the load is fixed at $50 \Omega$. When the load impedance is $<50 \Omega$, such as seen during our energy deliveries at a setting of $300 \mathrm{~J}$, a greater percentage of the energy stored in the storage capacitor will be dissipated in the internal resistance of the defibrillator circuitry. In the extreme, when the load impedance is zero, no energy will be dissipated in the load.

Choice of catheter. Some groups report the use of a special catheter for His bundle ablation $(21,22,27$, 28) but we prefer a standard tripolar catheter and have used the distal pole on each occasion. We have found no evidence of catheter disruption, although we have found evidence of some delivery of energy (via a presumed capacitive coupling) through the proximal poles of the catheter. This has not affected the outcome and, using a standard catheter, we have used lower energy levels than that reported for the special catheters (28).

Conclusions. We conclude that catheter ablation of the normal AV conduction system is a safe and effective treatment for refractory supraventricular arrhythmias in properly selected patients. Its utilization must be undertaken with the possibility of complete pacemaker dependence and the patients selected must be investigated carefully beforehand to document the mechanism of the tachycardia and exclude multiple accessory pathways of conduction.

The characteristics of energy delivery are complex and require a complex time-varying impedance to accurately model the energy delivery. This complex impedance is due to changes occurring at the electrode-tissue interface rather than a property of the catheter per se.

No characteristic of energy delivery allows the prediction of successful His bundle ablation.

The catheters used in this study are capable of withstanding the current flow required without physical disruption, although occasional open circuits are seen that do not affect energy delivery during the shock that produces the open circuit. 


\section{ACKNOWLEDGMENTS}

The authors would like to thank Laura Cook, R.N. of the Electrophysiology Laboratory; University Photography and Illustration for the preparation of the illustrations; and Mrs. Mary Holben, Mrs. Bettie McDade, and Mrs. Sue Chiaramonti for typing the manuscript and coordinating patient care

This work was supported, in part, by the National Heart, Lung, and Blood Institute grants HL-155190 and HL 06258-01.

\section{REFERENCES}

1. Giannelli, S. Jr., S. M. Ayres, R. F. Gromprecht, E. F. Conklin, and R. J. Kennedy. 1967. Therapeutic surgical division of the human conduction system. JAMA (J.Am. Med. Assoc.). 199:155-160.

2. Slama, R., P. Blondeau, J. Aigueperse, J. Cachera, M. Degeorges, et E. Albou. 1967. Creation chirugicale d'un block auriculoventriculaire et implantation d'un stimulateur dans deux cas de troubles du rhythme irreductibles. Arch. Mal. Coeur. 60:406-422.

3. Dreifus, L. S., H. Nichols, D. Morse, Y. Watanabe, and R. Truex. 1968. Control of recurrent tachycardia of WolffParkinson-White syndrome by surgical ligature of the A-V bundle. Circulation. 38:1030-1036.

4. Latour, H., P. Puech, R. Grolleau, P. A. Chaptal, et R. Dufoix. 1970. Le traitement chirurgical des accès de tachycardie paroxystique graves du syndrome de WolffParkinson-White et ses limites. Arch. Mal Coeur. 62:977989.

5. Dunaway, M. C., S. B. King, Jr., C. R. Hatcher, Jr., and R. B. Logue. 1972. Disabling supraventricular tachycardia of Wolff-Parkinson-White syndrome (type A) controlled by surgical A-V block and a demand pacemaker after epicardial mapping studies. Circulation. 45:522-528.

6. Edmonds, J. H., Jr., R. G. Ellison, and T. L. Crews. 1969. Surgically induced atrioventricular block as treatment for recurrent atrial tachycardia in Wolff-ParkinsonWhite syndrome. Circulation. 39 and 40(Suppl. 1):1105-111.

7. Cole, J. S., R. E. Willis, L. C. Winterscheid, D. D. Reichenbach, and J. R. Blackmon. 1970. The Wolff-Parkinson-White syndrome: problems in evaluation and surgical therapy. Circulation. 42:111-121.

8. Sealy, W. C., R. W. Anderson, and J. J. Gallagher. 1977. Surgical treatment of supraventricular tachyarrhythmias. J. Thorac. Cardiovasc. Surg. 73:511-522.

9. Sealy, W. C., D. B. Hackel, and A. V. Seaber. 1977. A study of methods for surgical interruption of the His bundle. J. Thorac. Cardiovasc. Surg. 73:424-430.

10. Harrison, L., J. J. Gallagher, J. Kasell, R. W. Anderson, E. Mikat, D. B. Hackel, and A. G. Wallace. 1977. Cryosurgical ablation of the AV node-His bundle: a new method for producing A-V block. Circulation. 55:463470.

11. Gallagher, J. J., W. C. Sealy, R. W. Anderson, J. Kasell, E. L. C. Pritchett, L. Harrison, and A. G. Wallace. 1977. The surgical treatment of arrhythmias. In Reentrant Arrhythmias. H. E. Kulbertus, editor. MTP Press, Ltd., Lancaster, England. 351-365.

12. Klein, G. J., W. C. Sealy, E. L. C. Pritchett, L. Harrison, D. B. Hackel, D. Davis, J. Kasell, A. G. Wallace, and
J. J. Gallagher. 1980. Cryosurgical ablation of the atrioventricular node-His bundle: long-term follow-up and properties of the junctional pacemaker. Circulation. 61:8-15.

13. Sealy, W. C., J. J. Gallagher, and J. Kasell. 1981. His bundle interruption for control of inappropriate ventricular responses to atrial arrhythmias. Ann. Thorac. Surg. 32:429-438.

14. Williams, J. C. P., and E. H. Lambert. 1964. Production of heart block in dogs without thoracotomy. Fed. Proc. 23:413a. (Abstr.)

15. Turina, M. I., I. Babotai, and W. Wegmann. 1968. Production of chronic atrioventricular block in dogs without thoracotomy. Cardiovasc. Res. 2:389-393.

16. Babotai, I., and R. Brownlee. 1971. Experimental atrioventricular block without thoracotomy: a new instrument. Cardiovasc. Res. 5:416-418.

17. Randal, O. S., N. Westerhof, G. C. van den Bos, and P. Sipkema. 1981. Production of chronic heart block in closed-chest dogs: an improved technique. Am. J. Physiol. 241:H279-282.

18. Fisher, V. J., R. J. Lee, L. C. Christianson, and K. Kavaler. 1966. Production of chronic atrioventricular block in dogs without thoracotomy. J. Appl. Physiol. 21:11191121

19. Beazell, J., K. Tan, J. Criley, and J. Schulman. 1976. The electrosurgical production of heart block without thoracotomy. Clin. Res. 24:137a. (Abstr.)

20. Beazell, J. W., K. S. Tan, J. L. Fewkes, M. Furmanski, and D. A. Fisher. 1977. Technique for production of permanent lesions in the intracardiac conduction system. Clin. Res. 25:141a. (Abstr.)

21. Gonzalez R., M. M. Scheinman, W. Margaretten, S. Bharati, and M. Lev. 1981. Closed-chest permanent atrioventricular block in dogs: techniques and anatomic changes. Am. J. Cardiol. 47:428a. (Abstr.)

22. Gonzalez, R., M. M. Scheinman, W. Margaretten, and M. Rubinstein. 1981. Closed-chest electrode-catheter technique for His bundle ablation in dogs. Am. J. Physiol. 241:H283-287.

23. Bardy, G. H., J. H. Kasell, R. E. Ideker, S. J. Worley, W. M. Smith, L. D. German, and J. J. Gallagher. 1982. Transvenous catheter ablation of the atrioventricular conduction system for treatment of refractory supraventricular tachycardia: electrophysiologic and pathologic observations in dogs. Am. J. Cardiol. 49:1012a. (Abstr.)

24. Vedel, J., R. Frank, G. Fontaine, J. F. Fournial, et Y. Grosgogeat. 1979. Bloc auriculo-ventriculaire intra-Hisian definitif indult au cours d'une exploration endoventriculaire droite. Arch. Mal. Coeur. 72:107-112.

25. Gallagher, J. J., R. H. Svenson, J. H. Kasell, L. D. German, G. H. Bardy, A. Broughton, and G. Critelli. 1982. Catheter technique for closed-chest ablation of the atrioventricular conduction system. N. Engl. J. Med. 306:194200.

26. Gallagher, J. J., R. H. Svenson, J. H. Kasell, L. D. German, G. H. Bardy, A. Broughton, and G. Critelli. 1982. Catheter technique for closed-chest ablation of the atrioventricular conduction system in man. Am. J. Cardiol. 49:1012a. (Abstr.)

27. Scheinman, M. M., F. Morady, D. Hess, and R. Gonzalez. 1982. Transvenous catheter technique for induction of damage to the atrioventricular junction in man. Am. J. Cardiol. 49:1013a. (Abstr.)

28. Scheinman, M. M., F. Morady, D. S. Hess, and R. Gon- 
zalez. 1982. Catheter-induced ablation of the atrioventricular junction to control reciprocating supraventricular arrhythmias. JAMA (Am. J. Med. Assoc.). 243:851855.

29. Broadman, R., and J. D. Fisher. 1982. Technique for ablation of anomalous conduction using catheter placed in coronary sinus: canine studies. Circulation. 66:II217a. (Abstr.)

30. Broadman, R., and J. D. Fisher. 1983. Evaluation of a catheter technique for ablation of accessory pathways near the coronary sinus using a canine model. Circulation. 67:923-929.

31. Fisher, J. D., R. Broadman, S. G. Kim, and J. A. Matas. 1982. Nonsurgical Kent bundle ablation via the coronary sinus in patients with Wolff-Parkinson-White syndrome. Circulation. 66:1I-375a. (Abstr.)

32. Hartzler, G. O. 1983. Electrode catheter ablation of focal ventricular tachycardia. J. Am. Coll. Cardiol. 1:595a. (Abstr.)

33. Ewy, G. A., R. D. Fletcher, and M. D. Ewy. 1972. Comparative analysis of direct current defibrillators. J. Electrocardiol. 5:349-354.

34. Tacker, W. A., Jr., L. A. Geddes, and Van Vleet, Jr. 1980. Cardiac damage by defibrillation. In Electrical Defibrillation. CRC Press, Boca Raton, FL. 137-153.

35. Broughton, A., J. J. Gallagher, L. D. German, T. Guarnieri, and J. L. Trantham. 1983. Escape rhythm properties following His ablation by the catheter technique. J. Am. Coll. Cardiol. 1:635a. (Abstr.)

36. Dymond, A. M. 1976. Characteristics of the metal-tissue interface of stimulation electrodes. IEEE Trans. Biomed. Eng. 23:274-280.

37. Rush, S., J. A. Abildskov, and R. McFee. 1963. Resistivity of body tissues at low frequencies. Circ. Res. 12:40-50. 